\title{
Técnica Sanitária e o Traçado da Cidade: Representações de Planta e Plano no Trabalho do Urbanismo em Pernambuco na Década de 20*
}

\author{
José Tavares Correia de Lira
}

Resumo

Neste artigo procuramos acompanhar as representações de plano de extensão e planta da cidade, pelas quais a engenharia sanitária estabeleceu os seus procedimentos no âmbito do urbanismo. Acompanhamos as discussões do Recife entre os anos 10 e 20, através do discurso de engenheiros como Moraes Rego, Saturnino de Brito, José Estelita e Paulo Guedes, que, atraídos pelo debate internacional, avançaram na definição de um campo separado de preocupações. Ainda que comprometidos com a eugenia e a paisagem, estes engenheiros, em suas pretensões científicas e formulações conceituais, gradualmente se afastam do campo da medicina e da arte. Os liames desse processo, exemplarmente resumidos em um tal traçado sanitário da cidade, podem ser entrevistos na analogia do corpo urbano, bem como na ligação orgânica entre solo, subsolo e superfície, tanto quanto entre a planta e o plano.

\footnotetext{
Abstract

This article tries to examine issues that bind together plan of extension to mapping of a town as a sort of representation inaugurated from sanitary engineering concerns. It focuses on discussions taken place in Recife, Brazil, during the 1910s and 1920s, when the international debate on "town planning" drew the attention of local engineers such as Moraes Rego, Saturnino de Brito, Paulo Guedes and José Estelita. Even though their former interestes being rested upon hygiene and landscape, they were gradually moving to recognize urbanistic problems as an autonomous field of analyses and intervention. From this new perspective, the town is to be considered analogous to the human body with its proper anatomy and patology, just as much as a combination of soil, subsoil, superficies and constructions.
} 
"La muralla tenaz que en este momento y en todos, proyecta sobre tierras que no veré, su sistema de sombras, es la sombra de un Cesar que ordenó que la más reverente de las naciones quemara su pasado."

Jorge Luis Borges

(1) FREYRE, Gilberto. Sobrados e mucambos. Decadência do patriarcadorurale desenvolvimen to do urbano. 2. ed. Rio de Janeiro: José Olympio. 1951, p. 585-6.

Planta da Cidade do Recife. 1906.

Reduzida dos levantamentos da cidade feitos por sir Douglas Fox e socios e Michel Whitley.

Fonte: Arquivo Público Estadual Jordão Emerenciano. Recife.
A referência de Gilberto Freyre à urbanização holandesa do Recife no século 17 , tornou-se um mito de origem também nos escritos de engenheiros pernambucanos seus contemporâneos, sobretudo quando se tratava de criticar a malha histórica tradicional da cidade como espaço decadente, sujo, escuro, abafado, insalubre, de todo inadequado a uma orientação racional em matéria de urbanismo. Não em Casa Grande \& Senzala, mas em Sobrados e Mucambos, livro de 1936, "o Recife judaico-holandês" é apresentado como "o maior centro de diferenciação intelectual na colônia, que o esforço católico no sentido de integração procurava conservar estranha às novas ciências e às novas línguas. (...) Peter Post traçando os planos de uma grande cidade de sobrados altos e de canais profundos por onde se pudesse passear de canoa como na Holanda" ${ }^{1}$. A urbanização da cidade datando, de fato, "do Recife holandês - primeiro ponto do

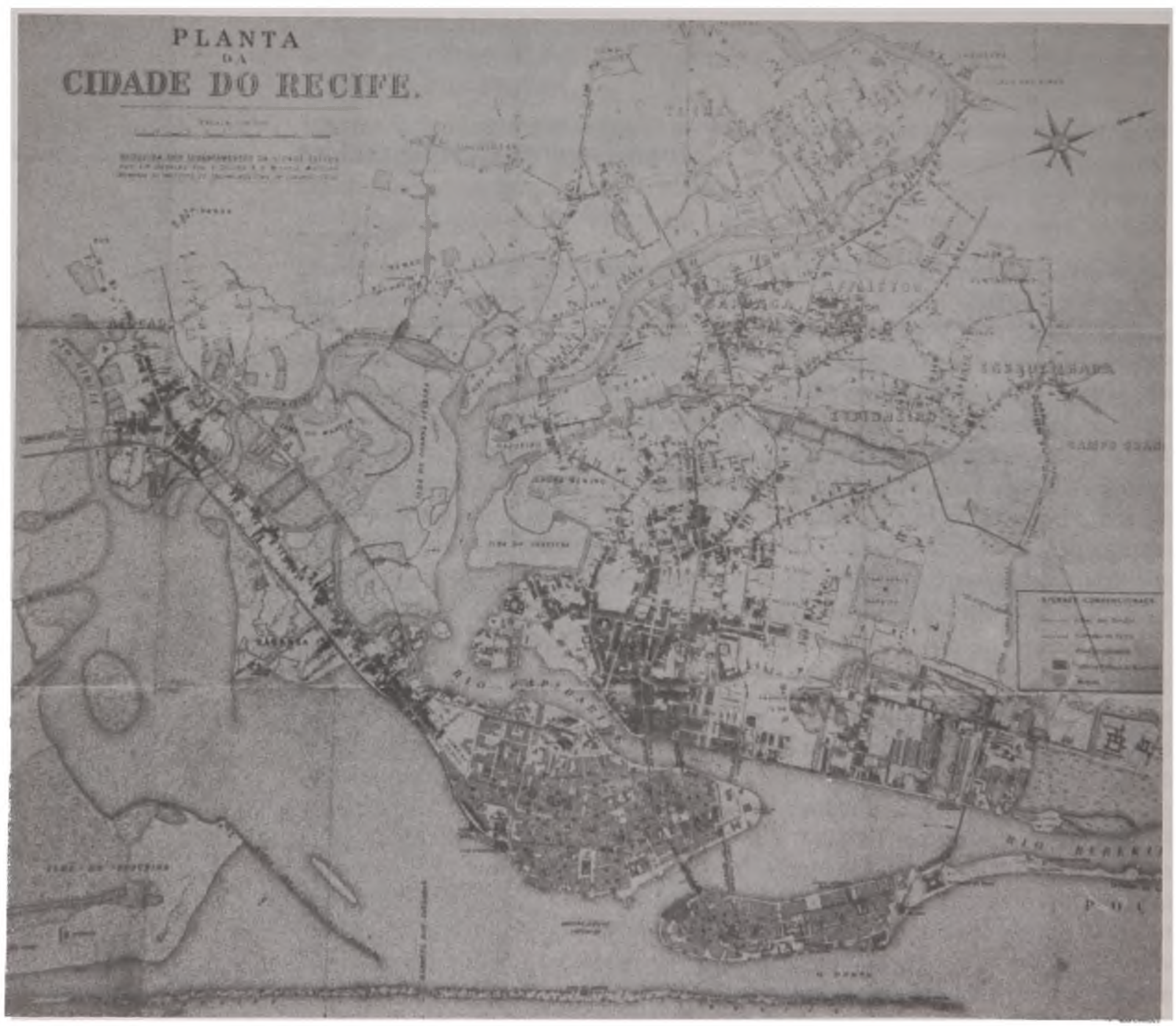


Brasil colonial a amadurecer em cidade moderna, as preocupações de comércio dominando os militares e juntando-se às próprias condiçōes topográficas, no sentido de comprimir a população e verticalizar a arquitetura. (...) Plana e sem morros que formassem bases naturais a altos e baixos sociais. Banhada e servida também pelas camboas do plano de urbanização do engenheiro Post e desafogada pelas pontes, mandadas construir por Maurício de Nassau e que permitiram a expansão da área urbana"2. Assim, não apenas o Recife como "cidade moderna", mas o "plano de urbanização" dos holandeses tem reaparecido inúmeras vezes como base de formação da disciplina urbanística. Assim, o já clássico Tempo dos flamengos, de José Antonio Gonsalves de Mello, veio apenas confirmar, em 1947. essa precedência do "plano urbanístico" nassoviano, senão com Peter Post, ou outro engenheiro qualquer como Pistor, ou mesmo com Marcgrave, sempre sob a orientação do conde holandês ${ }^{3} 0$ mapa assinado por Cornelis Golijath, datado de 1648, é ilustrado com uma belíssima planta da cidade Maurícia em que se destaca o assentamento recente dos holandeses na ilha de Antonio Vaz com suas ruas cortadas regularmente, saneamento e sistema de canais, pontes e diques: atestado de nascimento, para muitos, de um planejamento urbano racional no Brasil.

Também nos anos 40, a transcrição, tradução e publicação no Brasil do Diário intimo do engenheiro Vauthier (1840-1846) viria a propor uma ponte entre o "urbanismo" dos anos de Maurício de Nassau (1637-1644) e o dos anos de Francisco do Rego Barros (1837-1844), e de ambos com as obras a serem enfrentadas pelos engenheiros urbanos e urbanistas dos anos '30 e 40' deste século. Gilberto Freyre, não por acaso, é quem organiza e apresenta o diário e publica em 1940 o seu Um engenheiro francês no Brasil ${ }^{4}$ Agora, Louis Léger Vauthier ao lado de Boulitreau, particularmente envolvido nas obras urbanas, são definitivamente consagrados como urbanistas "avant la lettre" $\mathrm{Na}$ Introdução do anotador às cartas de Vauthier sobre casas de residência no Brasil, publicadas em português, tanto a introdução de Freyre quanto as cartas de Vauthier, em 1943, lê-se: "O arquiteto Vauthier parece ter sido também no Brasil um mestre de higiene - higiene doméstica, higiene urbana, higiene pública - pela melhor distribuição de salas, cozinha, quartos de dormir (...); e pelos seus esforços unidos aos de médicos brasileiros e aos do engenheiro Bloem - a favor da melhor distribuição de casas em áreas cívicas, de residência e de comércio, de inteligente zoneamento de atividades na cidade do Recife. Burgo crescido tão irregularmente quanto qualquer outra cidade portuguesa depois que daqui se foi com seus artistas e seus técnicos o grande Maurício de Nassau"5. Vauthier está, portanto, em linha de continuidade com Nassau, mas também com a obra dos higienistas, e seus trabalhos do Recife em favor de um "plano regional" tem como alvo a cidade portuguesa concebida genericamente como cidade irregular. Aliás, na introdução do mesmo, de 1956, o paralelismo se completa na referência à urbanística moderna. Vauthier, precursor de um ecologismo tropical no Brasil, anteciparia as preocupações de urbanistas contemporâneos como um Patrick Abercrombie ou um Alfred Agache ${ }^{6}$.

Não seria aqui o caso de contestar a hipótese do nascimento do urbanismo no Brasil pelas mãos dos holandeses no século 17. Em sua tese de 1964, Contribuição do estudo da evolução urbana no Brasil (1500/1720), Nestor Goulart Reis Filho, mostrou não ser característica interna dos planos portugueses, nem mesmo em suas cidades coloniais, a mera irregularidade, atributo que os autores dos anos 30 não se cansaram de enfatizar ${ }^{7}$ Sobrados e mucambos, aliás, como também Raízes do Brasil, de Sérgio Buarque de Holanda, como possivelmente os
(2) Idem, p. 390-1.

(3) MELLO, José Antônio Gonsalves de. Tempo dos flamengos. Influência da ocupação holandesa navida e na cultura do norte do Brasil. 3. ed. Recife: Massangana, 1987.

(4) FREYRE, Gilberto. Um engenheiro francess no Brasil. Rio de Janeiro: José Olympio, 1940. (Coleção Documentos Brasileiros). Parte integrante da "engenharia social" que se enaltecia, o projeto da planta do Recife e dos Arrabaldes (1840-42), traçada a círculo de borda, é apresentada por Freyre (p. 116 e 170) como umatestado da visāo de conjunto e da orientação moderna e cientifica do planejamento não somente urbano, mas regional, de Vauthier. Nada importando sequer que a planta não tivesse sido concluída.

(5) Idem. 2. Tomo. 2. ed. Rio de Janeiro: José Olympio, 1960; p. 796.

(6) Idem, p. 514-5.

(7) REIS FILHO, Nestor Goulart. Contribuição ao estudo da evolução urbana do Brasil (1500/1720). Sāo Paulo: Pioneira, 1968. Conforme os estudos de Goulart, mesmo a urbanização portuguesa no Brasil teria obedecido a certas regras, mobilizado certos conhecimentos, técnicas e instituiçōes. requerido a intervençāo de profissionais; podendose falar até de uma "urbanização regular" de vilas e cidades portuguesas no Brasil, e não de um processo aleatório de ocupação. Os ambiciosos programas de urbanizaçāo dos períodos joanino e pombalino no Brasil, os planos de Salvador e São Luís, ainda no começo do século 17, entre outros exemplos, valendo para desmontar a antiga hipotese. 
exemplos mais influentes dessa tendência, inclusive quanto ao contraste entre as cidades portuguesas e a regularidade do plano holandês. A leitura por Nestor Goulart do livro de Mário Chicó, A cidade ideal do renascimento e as cidades portuguesas da India (1956), a ele apresentado coincidentemente no Recife por José Maria de Albuquerque e Mello, veio comprovar o equívoco de uma generalização acerca do "urbanismo" português. Mais ainda, "tendo em vista que os portugueses adotaram no Brasil, no século 16, uma política geral diferente da que seguiam na Índia, nessa época e da que era empregada pelos espanhóis na América, é possível entender que também a sua política urbanizadora fosse diferente no Brasil e apresentasse resultados diferentes, como ocorreu com as redes urbanas das diversas capitanias.(...) Um fato é incontestável: os holandeses aplicaram no Brasil política urbanizadora semelhante, concentrando seus interesses no Recife e conservando a rede dos pequenos centros tal qual a receberam dos portugueses. Se capacidade técnica fosse suficiente para transformar toda uma política urbanizadora, os holandeses deveriam ter alterado, para melhor, os esquemas dos núcleos de toda a imensa área que dominaram no Brasil, o que de fato não ocorreu. Colocados em face à mesma realidade dos portugueses, comportaram-se de forma extremamente semelhante a esses " 8

Em suma, com este estudo, o contraste portugueses/espanhóis ou portugueses/ holandeses enquanto um contraste entre um suposto "não-urbanismo" e um "urbanismo" regular precisaria ser revisto. Mas, ainda que seja interessante relacionar a fundação planejada de cidades ao gesto pioneiro de tomada de posse de um lugar e defesa de um território, há sempre o risco de se compreender a criação de cidades através da definição militar dos assentamentos que a experiência colonial nos sugere. Ou melhor, há sempre a tentação de se estabelecer uma continuidade necessária entre o urbanismo, que se estabelece como disciplina no final do século 19 , e a edificação articulada de cidades fortificadas no interior de uma estratégia mais ampla de domínios de terra muito mais vastos. Parece que o professor Nestor não se preocupou em fazer a crítica dessa perspectiva transhistórica em que se enredaram autores diversos, como Gilberto Freyre, e engenheiros e arquitetos voltados para a elaboração do plano de cidades ao menos até a primeira metade do século 20 .

Por outro lado, se pensarmos em 1848 e na oposição política nativista ao barâo da Boa Vista, deve ser instigante para os historiadores a sugestão que os anos 30 e 40, deste século, nos fizeram quanto ao elo entre os séculos 17 e 19, entre Nassau e Vauthier. Valeria à pena, de certo, acompanhar o imaginário genealógico que recobriu o urbanismo de passado tão arcaico quanto a empreitada da Companhia das Índias Ocidentais no Recife (nos oito breves anos de paz em que, entre 1630 e 1654, foi possível experimentar, sem sucesso, a implantação de instituições e valores holandeses na sociedade colonial que se formava), ou tão localizado quanto a atuação da Repartição de Obras Públicas em Pernambuco no segundo terço do século 19.

Obviamente não pode ser objeto deste artigo demonstrar como esse imaginário se produziu historica e psicologicamente, desconhecendo cortes históricos e epistemológicos, se é que podemos dizer assim, para a produção da disciplina urbanística. Trata-se apenas de caracterizá-la em um debate localizado e datado: entre os "engenheiros-urbanistas" dos anos 10 e 20 no Recife. Será bastante se esse conjunto discursivo sinalizar para as profundas transformações que neste momento se processam no âmbito da administração das coisas da cidade. $O$ fato deles eventualmente se verem em continuidade com os engenheiros franceses 
e holandeses de outrora diz muito pouco a respeito do saber com que operam. As obras e os planos do passado - reafirmamos - são antes um sinal da antigüidade e autoridade reivindicadas pela nova ciência urbanística que propriamente um acervo empírico e teórico relevante na prática e discurso profissionais que lhes são peculiares. Quase tudo é ou deve ser novo para o urbanista, ainda que se tenha que lidar com as obras públicas do século 19 ou com a situação topográfica eleita nos começos do assentamento; de certo alguns motivos de preocupação e recursos instrumentais serão conservados, e mesmo que, ainda no período colonial ou imperial, seja possível observar elementos como a drenagem superficial dos baixios, o abastecimento d'água, o saneamento, a formação dos arruamentos e quadras e mesmo o controle e indução do crescimento de certas áreas da cidade - que se tornariam caros à urbanística moderna, o recurso às experiências e idéias contemporâneas dará o tom da ruptura que se ensaia.

Assim, se não é nova a idéia de planta, nem a idéia de plano da cidade, é sem dúvida recente a ligação que o urbanismo fez entre uma e outra: articulou os dados fisiográficos do espaço e as superfícies habitadas à edificação das novas paisagens e maquinarias subterrâneas, ao mesmo tempo em que reuniu a geologia, a topografia, a hidráulica, a arquitetura e o gênio civil em uma disci-plina que não será mais puramente definida por suas obras, de levantamento ou melhoramentos, mas por suas projeçōes sobre o solo natural e/ou a cidade histórica.

O reformismo urbano oitocentista, em seus contrastes entre as cidades existentes e as novas, nos legou um campo heterogêneo de representações gráficas e cartográficas de usos variados. Aliás, desde o começo do século 19, o nível especulativo em que se inseria o mapa da cidade, pouco a pouco deixou-se permear por coordenadas geográficas dignas de prova de medição e localização, tornando-se então cada vez mais desembaraçado dos mitos e conjecturas que o preenchiam de muitos sentidos. No entanto, a planta da cidade que os urbanistas agora pediam era algo distinto de suas congêneres anteriores. Desligado dos erros do passado, do carvão, do lápis mal aparado, o "tira-linhas" do profissional representa nova e judiciosa orientacão. Medidas empiricamente observáveis por meio de critérios e aparelhos específicos, e "localizações relativas" dotadas de alguma qualidade estratégica. Não somente a planta extrapolava os limites usuais do território urbano, mas se enredava nos marcos da geodésia. A idéia de situação local, topográfica, evidenciaria as dependências entre a paisagem natural e o assentamento; a idéia de posição geral geográfica estabeleceria as conexões entre o organismo urbano e os fundamentos geográficos da região, situando-a também no resto do mundo.

Tratava-se não apenas de melhorar o centro decaído da cidade, mas de prever o seu desenvolvimento, ou seja, além do núcleo habitado e habitável, e do mercado local, tratava-se de observar os acidentes da geografia, os favores e barreiras da topografia e da hidrografia, de modo que o crescimento dos portos, das estações e linhas ferroviárias, dos canais e estradas, tudo isso que as obras públicas do século 19 definira como estratégia, pudessem ser previstos ou projetados racionalmente na expansão do assentamento original. Agora, dois princípios geográficos-chave serão postos em relação e aplicados teoricamente: o de localização e o de extensão. Relacionados, tentarão dar conta da totalidade da cidade e de suas linhas de desenvolvimento em plano definitivo. Desse modo, a carta geográfica tornar-se-á a base do trabalho do urbanista e o "plano de 
(9) BRITO, Saturnino. Saneamento do Recife. In: Obras Completas de Saturnino de Brito. v. VIII, Rio de Janeiro: Imprensa Nacional, 1944

(10) ESTADO DE PERNAMBUCO. Relatório apresentado ao exmo. sr. dr. Herculano Bandeira de Mello, governador do Estado, pelo Secretário Geral do Estado, bacharel José Osório de Cerqueira, em 31/01/1910. Recife: Typographia do Diário de Pernambuco, 1910, p. 93.
Planta da Cidade Maurícia.

Reprodução do Mapa de Caspar Baerle "Rerum per Octennium in Brasilia (1636-44).

Fonte: Castro, J. A Cidade do Recife: ensaio de geografia urbana. Rio de Janeiro. Casa do Estudante do Brasil, 1954. conjunto", articulando saneamento e remodelação com a extensão da cidade, recobrirá a nova planta.

\section{Reforma da Planta da Cidade, Topografia e Cadastro}

Já em 1916, a planta do Recife de Douglas Fox, elaborada em 1906, base das reformas do porto e do Recife antigo, aparece como obra limitada, não fornece informações suficientes sobre a totalidade da cidade e de seus subúrbios, restringindo como tal a ação beneficiadora da administração municipal ${ }^{9}$. Antes disso, aliás, entre 1909 e 1910, o trabalho da comissão de saneamento da cidade já precisara completar os estudos topográficos de Fox, fazendo contar os prédios de todos os quarteirões e colocando em todas as plantas as curvas de nível, de 25 em 25 centímetros $^{10}$. Em 1916 é organizada uma comissão especial para a execução da nova planta. Os engenheiros civis tomam a frente: Miguel de Oliveira; depois Nestor Moreira Reis e João Holmes Sobrinho, o astrônomo; em

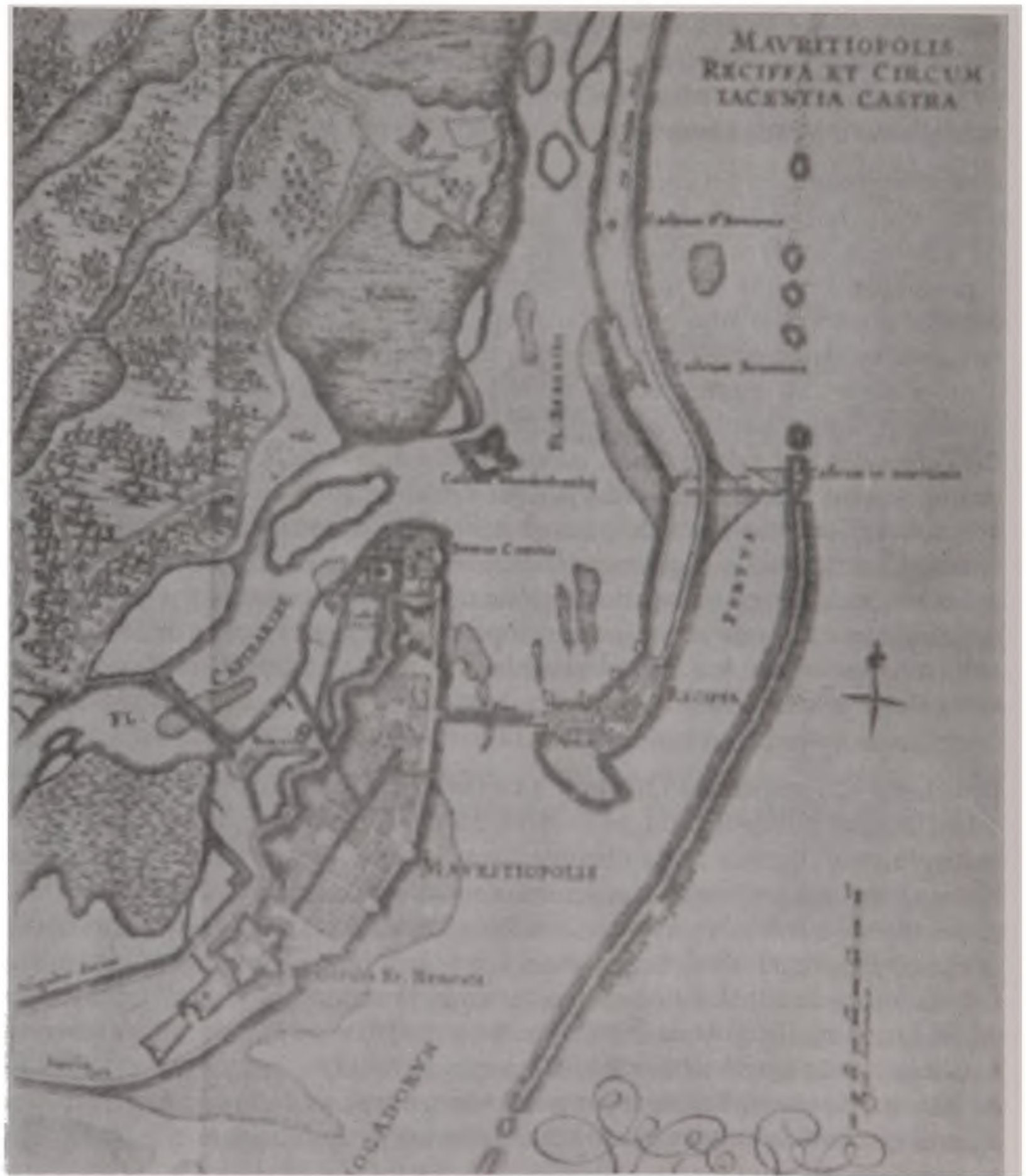


1919, a comissão Geodésica é dirigida pelo engenheiro civil Domingos Ferreira. A planta de 1906 é questionada. "Assim limitada" diz em 1919 o engenheiro Moraes Rego, então prefeito do município, "nada comprehendendo, por assim dizer, da parte do municipio onde a cidade vae aos poucos surgindo e onde com mais efficacia directora do poder publico, de modo a se conseguir, economicamente, des de a nascença, uma cidade hygienizada e formosa, vê-se immediatamente que essa planta nenhum subsidio fornecia para a organização definitiva de um projecto geral de melhoramentos, a que deve obedecer systematicamente a acção directora da municipalidade" "

É plausível que Moraes Rego se exprima no registro da higiene e da estética urbana, tendo recentemente acompanhado a reforma do bairro do Recife (19091913) e a implementação do plano de esgotamento sanitário do Recife (19091919), o plano de saneamento de Saturnino de Brito. Higiene e estética são pois pressupostos do novo plano. Mas o que Moraes Rego entende como "projeto geral de melhoramentos" envolve um conjunto mais abrangente de questões: segurança e facilidade de tráfego, alargamento e retificação das ruas, calçamento moderno, arborização, jardins e calçadas, boeiros e pontilhões, numeração predial, iluminação, instrução pública, mercados e feiras, enfim, "tudo quanto constitue o já hoje perfeitamente definido problema do urbanismo nas grandes capitaes" ${ }^{12}$. Se o termo urbanismo já é empregado sem hesitação, o que dizer da planta do município? Ora, a nova planta deve reunir os indicadores visuais do problema urbano: a demarcação administrativa, a situação higiênica e hídrica, os acidentes geográficos, as linhas de tráfego, as quadras, os lotes e as partes edificadas da cidade. E essa ainda resta ser feita.

Na verdade o que então se propõe é algo próximo às anotações de Baeta Neves sobre a planta topográfica, durante os seus trabalhos de Minas Gerais, já preconizado à época do plano de esgotamento sanitário do Recife, entre $1909 \mathrm{e}$ 1910, e freqüentemente resgatado pelos engenheiros dos anos de 1920. Em 1918, Saturnino de Brito divulga em congresso dos prefeitos de Pernambuco a caderneta n.1 de Neves. Ele cita os trabalhos de engenharia sanitária: "para a organização de um projeto geral de melhoramentos, de expansão e saneamento, é preciso proceder ao levantamento da planta topográfica da cidade e de seus arredores" ${ }^{13}$. Ele elabora as suas próprias cadernetas; a número 1 trata dos "Estudos e Serviços Preparatórios" 14: levantada agora com fita de aço, com correçōes de dilatação e redução ao horizonte, com fechamento rigoroso dos polígonos e coordenadas calculadas a esquadros, a planta topográfica rigorosa conterá apenas os detalhes essenciais para o projeto e a execuçāo dos serviços sanitários; nela, bastará a representação fiel das frentes dos edifícios.

Tudo isso sob as malhas geométricas da representação geodésica; no caso: a planta por triangulação em rede. Ora, a geodésia é essa ciência que estabelece a relação entre os acidentes naturais e a sua localização no território, estabelecendoa por recortes técnicos em forma de "marcos" A triangulação materializa uma coordenada qualquer pela disposição destes pequenos tijolos de cimento nos vértices dos triângulos sob os quais, altura e curvatura de um solo natural, se desenvolvem; apreende assim sua superfície em área e em nível relativo. A precisão é portanto fundamental: um erro de localização e de medição compromete toda a divisão do terreno e estabelecimento da rede. A planta geodésica será pois o ponto de partida para se traçar o desenvolvimento de uma cidade, vertical e horizontalmente: extensão de vias, drenagem, movimentações de terra, aparelhagem higiotécnica, fundações, loteamentos, tudo o que diz respeito à ocupação da cidade deverá ser adequado às possibilidades do terreno.
(11) PREFEITURA MUNICIPAL DO RECIFE. Exposição com que o Dr. Manoel Antonio de Moraes Rego, prefeito do municlpio do Recife. abriu a quinta e última sessão do Conselho Municipal, no dia 15 de novembro de 1919. Recife: Imprensa Industrial, 1919, p.38.

(12) Idem, p. 4.

(13) BRITO, F. S. de. Notas para o congresso dos prefeitos de Pernambuco. (1918). In: Obras Completas. v. XX, Rio de Janeiro: Imprensa Nacional, 1944.

(14) In: Obras Completas. v, IV, p.179-80. 
(15) ESTELITA, J. A remodelação do Recife e a engenharia sanitária. In: Boletim de Engenharia, $\mathrm{n}$. 2. v. III, Recife, dez. 1927, ano V, p. 54

(16) In: Obras Completas, v. VI, p. 35-6.

(17) Informações. As cidades sem planta. In Boletim de Engenharia, n. 9, v. II, Recife, anno V. p. 246-7, jun. 1927. Trata-se de uma referência a Armando Godoy.

(18) GODOY, A. A urbs e os seus problemas. Rio de Janeiro, Jornal do Commercio, 1943.

(19) ANDRADE, C. R. M. de. A peste e o plano: 0 urbanismo sanitarista do engenheiro Saturnino de Brito. São Paulo: FAUUSP, 1992, p.143.
Enraizada no solo, como um vegetal, a "planta" permite visualizar a "marcha evolutiva" da cidade. Eu cito José Estelita: "No estudo preliminar do traçado começa logo o engenheiro civil, sendo o primeiro a agir, procurando fixar sobre um plano a figura do terreno por intermédio da triangulação, da planimetria e do nivelamento. Ainda ao engenheiro civil compete fazer o estudo das sondagens geológicas, o estudo completo dos portos marítimos e dos portos fluviais, das redes de comunicação interna e externa, das gares, das linhas de tramways, etc." ${ }^{15}$. Se se define a competência profissional para o trabalho da planta, também se define o método: geometria e geologia fundem-se aqui em geodésia, que se funde à engenharia dos transportes.

Mas o que se está a dizer é que, se é inevitável o progresso que atinge as cidades contemporâneas, é preciso saber como adaptá-las à marcha de sua evolução, mas também o seu solo e o seu subsolo. Temos assim pois a necessidade que a planta seja ao mesmo tempo geodésica e topográfica, mas também cadastral, ou seja, que registre tudo o que se fez de novo nos bairros já levantados, "os acréscimos" sofridos pela cidade: prédios, muralhas, canais, muros, dependências, natureza dos calçamentos, galerias, canalizaçōes diversas, arborização, linhas de bondes, posteamento, etc. É Saturnino de Brito, em Saneamento de Campos (1903) quem nos define o "cadastro" como um registro municipal detalhado das propriedades públicas e privadas existentes na cidade e sobre o qual se elabora uma "planta cadastral" constando tanto dos dados topográficos do terreno quanto das construções e divisas que nele são elevadas ${ }^{16}$.

Portanto, o desenho da cidade se faz acompanhar de uma descrição e de um registro das modificaçoes de uso, posse, ocupação e aparelhagem que se fazem notar. A questão é reposta: "Como é possível sem uma planta completa resolver com ordem e segurança os problemas urbanos e projectar os melhoramentos? Como fazer funcionar regularmente certos órgãos da administração sem os dados, os esclarecimentos e indicações que nos proporcionam as folhas que formam a planta cadastral?" 17. A citação do engenheiro carioca Armando Godoy, ex-presidente da Comissão do Plano da Cidade do Rio de Janeiro, é necessária. Nos anos 20, Armando Augusto de Godoy tentava confirmar o urbanismo enquanto um ramo da engenharia. Sucessivos artigos de sua autoria na imprensa diária evidenciariam a autoridade do engenheiro quanto aos problemas de crescimento e remodelação das cidades. Em "O elemento fundamental da vida e das transformações urbanas"18, de novembro de 1926, ele reclamaria da suspensão das atividades da comissão da planta cadastral do Rio de Janeiro. 0 recurso à autoridade do mestre Pereira Reis coaduna-se aí com a denúncia da planta inexistente, obstáculo a uma administraçāo bem orientada. $O$ cadastro precisa constar de planta para que o administrador da cidade acompanhe de perto as transformações realizadas e se enraize no subsolo pois, "Urbanismo (agora) quer dizer ordem e harmonia entre todos os elementos da cidade, os subterrâneos, os superficiais e os elevados"

\section{Função Topográfica e Sanitária do Traçado}

Desde o final de 1909, Saturnino de Brito exerceria a direção da Comissão de Saneamento para elaborar e implantar o plano de esgotamento do Recife. Vale notar que a ausência de um levantamento topográfico adequado do Recife impedir-lhe-ia de formular um plano geral de expansāo para a cidade, à exemplo do de Santos ${ }^{19}$. Saturnino ficaria no Recife até o ano de 1918. Vanguarda do 
sanitarismo entre os engenheiros pernambucanos, sem restringir-se ao aparelhamento da cidade, Brito elaboraria algumas das formas de maior recorrência à intervenção profissionalizada no urbanismo, reunidas sob o nome de "higiotécnica" Em suas Notas para o congresso dos prefeitos de Pernambuco, em 1918, estão sistematizados os elementos principais de seu "plano de conjunto" para as municipalidades. O documento adianta um inventário das responsabilidades do engenheiro-urbanista: sobre a confecção do traçado das cidades, isto é, saneamento e aformoseamento; sobre os edifícios públicos e particulares; o "urbanismo" ou o traçado das cidades, congrega atribuições tão distintas quanto as comunicações e transportes, a produção de energia, a proteção ambiental, o saneamento. Trata-se agora de reuní-las em "um programa geral, racionalmente organizado, de modo a se estabelecer a harmonia entre os elementos e a se garantir a continuidade na execução" 20 .

Os trabalhos do Recife, sob a coordenação de Saturnino de Brito, são referência permanente no jovem círculo local de urbanistas; seja para saudar diretamente a doutrina sanitária adotada, seja para afiançar e reiterar toda uma literatura urbanística, particularmente francesa, que passa a circular e orientar investigações locais. Neste sentido, a Exposition de la cité reconstituée - Esthétique et Hygiene ${ }^{21}$ realizada em Paris, em meados de 1916, organizada pela Association Générale des Hygiénistes et Techniciens Municipaux, é um dos marcos legítimos da circulação aqui dessas novas idéias. É verdade que a exposição francesa está diretamente ligada a um manifesto pela reconstrução das cidades francesas e belgas atingidas pela guerra. No entanto, o que está em discussão são as próprias atribuições dos técnicos municipais no âmbito dessa disciplina mal conhecida que é o "urbanismo"; o próprio programa da exposição e o conteúdo das suas conferências demonstra que o que está em jogo é o problema genérico da cidade moderna, da higiene urbana, dos serviços municipais, da intervenção administrativa, através do qual se define o urbanismo em seu lugar histórico e social.

A participação de Saturnino de Brito no colóquio parisiense, possivelmente recebendo a "Mention de Hygiéne" e publicando no mesmo ano de 16 na França o seu "Notes sur le tracé sanitaire des villes" (escrito no Recife um pouco antes), sob o prefácio de Ed. Imbeaux, membro fundador da Associação Geral, parece ter sido o canal de acesso do grupo a toda uma literatura européia e norteamericana em matéria de planejamento de cidades. Desse modo, Sitte, Stubben, Hénard, Auburtin, Rey, Jaussely, Lewis, os colóquios de Lyon, Gand e Antuérpia tornar-se-iam referências locais na discussão sobre o "plano" da cidade.

Mas o livro de Saturnino é por certo contribuição específica à discussão corrente em urbanismo. Ao recusar tanto o título de "Town Planner" britânico, quanto o francês "Urbaniste", o autor prefere se apresentar por seus próprios trabalhos empíricos, uns e outros planos de saneamento e melhorias sanitárias de cidades brasileiras: Campos, Santos e Recife, são o atestado possível de seu discurso. Não é em vão que Saturnino de Brito usa a terceira pessoa para se referir a si: o "autor" atravessa reservadamente esse campo profissional e ideológico ainda mal-assumido; prefere definir-se pelo seu método: ao mesmo tempo higiênico, racional e estético, o "plan d'ensemble" combinaria internamente a idéia de saneamento com a de previsão do crescimento da cidade. Método "orgânico" pois tenta reconciliar o plano com a topografia, economizar nos traçados e abolir os riscos e caprichos do acaso: "o estudo crítico do desenvolvimento da vida urbana e suburbana, em quase todas as cidades do mundo, tem revelado graves defeitos na constituição orgânica dessas cidades, que se expandiram ao acaso
(20) BRITO, Op. cit. p.161.

(21) GAULTIER, L. Rapport Général. In: Exposition de la Cité Reconstituée - Esthétique et Hygiéne. Paris: Association Général de Hygiénistes et Techniciens Municipaux, 25 maio - 15 aout, 1916. 
(22) BRITO, F S. de. Discurso pronunciado no Ins-tituto Arqueológico Pernambucano a 27.01.1918. In: Obras Completas, v. XXII. Rio de Janeiro: Imprensa Nacional, 1944, p.137.

(23) GUEDES, P. Os planos de cidades. In: Boletim de Engenharia, n.4, v. II. Recife, ago. 1926, anno IV, p. 94.

(24) Idem. A planta da cidade. In: Boletim de Engenharia, n.3, v. II, Recife, jun.1926, anno IV, p. 67.

(25) Idem. A drenagem superficial do Recife. In: Boletim de Engenharia, n. 3, v. III, fev. 1928, anno VI, p. 72. por lhes faltar um programa racional previamente estudado" 22 Um organicismo, portanto, totalmente implicado na racionalização dos dados naturais: o organismo é pois feito por instrumentos organizados de tal modo que cumpram com determinadas funções do corpo.

$O$ interesse simultâneo pelo superficial e pelo subterrâneo é o que encontramos também no engenheiro Paulo Guedes, ligado, como José Estelita, ao círculo de urbanistas do Club de Engenharia de Pernambuco. Guedes confere ao " planejador de cidade" a tarefa de aproveitar artisticamente os acidentes do terreno, adaptando os traçados artísticos aos traçados sanitários ${ }^{23}$. Uma relação pois que parte do relevo para definir o escoamento dos fluidos, e daí procurar a maneira artística de construir a cidade; as obras sanitárias terão um traçado natural, as obras de urbanismo, um traçado higiênico; a estética urbana já será aquela na qual a forma segue a função topográfica e sanitária. A planta, como tradução detalhada das condições planimétricas e altimétricas do solo e do que nele e sob ele se encontra, será indispensável para a organização de um "plano de conjunto" Os dados geográficos serão necessários para a definição ou extensão das redes de canalizações subterrâneas, serviços e equipamentos coletivos, delimitação das quadras, do domínio dos lotes privados e edificações particulares. Quanto ao Recife: municipalidade alguma precisa tanto de uma planta completa; pobre de solo e de subsolo, pobre de terrenos, em geral alagados, construída pelas mãos imprevidentes dos mestres de campo e cordeadores coloniais, mal drenada, cheia de águas indomadas, com os escoamentos pluviais ademais esquecidos pelo saneamento da cidade, o Recife precisa urgentemente desse "plano de conjunto" "Quem olha para a planta, verifica a urgência de eliminar de tão formosa cidade, a área considerável de mangues, rectificando com canaes de cimento armado ladeados de bellas avenidas as linhas naturaes de escoamento" 24

A argumentação de Paulo Guedes, favorável às "linhas naturais do escoamento" e contrária aos mangues, parece contraditória. Não o é. Se o traçado urbano deve acompanhar o traçado sanitário, e este, a topografia, obviamente os mangues deverão ser disciplinados na geografia urbana, canalizados para liberar - e valorizar, ressalta o autor - os terrenos da paisagem natural inóspita, expulsando com ela o maior obstáculo ao urbanismo recifense: os mocambos, as habitações proletárias construídas irregularmente por toda a planície onde a água chega e alaga. Trata-se pois de disciplinar as tendências naturais da paisagem, mas também das populações. Em A drenagem superficial do Recife como factor importante para a sua salubridade, de 1928, o argumento eugênico agora transparece com maior clareza. A expulsão dos mocambeiros dos 1.182 hectares esgotados da cidade, $\circ$ aproveitamente via drenagem, das superfícies mal utilizadas e antiestéticas dos baixios cobertos de mangues e mocambos, é justificado em nome do "equilíbrio" Logo em seguida, escreve Guedes: "São duas sciencias que precisam caminhar emparelhadas, uma complementar da outra, a Hygiene e a Eugenia, de fins muito nobres, a primeira cuida da cidade, e a segunda aperfeiçoa a raça de cuja perfeição e vitalidade muito depende 0 progresso do Paiz. A acção beneficiadora dessas duas sciencias, porém annulase se a engenharia sanitária não lhes prepara o campo para exercerem seu nobilissimo fim" ${ }^{25}$. Ora, mas os mangues não são também elementos de regulação natural da paisagem? Sim, mas o ataque aos mangues é o álibi técnico para uma cruzada social que apenas se inicia: o ataque aos mocambos; a drenagem e a canalização dos alagados, ao mesmo tempo que permite conservá- 
los em sua função orgânica no corpo urbano, permite combater as causas de sua corrupção em elemento hostil à vida da cidade.

\section{O Corpo da Cidade e a Engenharia Orgânica}

O organismo-cidade aliás, é ainda mais complexo que o humano, pois sendo imortal pode eternamente permanecer doente, à espera de seu saneamento. A metáfora do médico é sedutora ao ser entrosada com a noção de organização urbana: "Chaque agglomération n'est évidemment q"un organisme particulier don le médecin, je veux dire l'urbaniste, doit étudier l'hérédité, les tares, le tempérament, la manière de vivre, les besoins et le développement futur" ${ }^{26}$. $O$ que Bonnier (Inspetor Geral dos Serviços Técnicos de Arquitetura e de Estética da Préfecture de la Seine) recupera aí é, metaforicamente, a idéia tradicional do diagnóstico das enfermidades. E como diagnosticar então? Primeiro, pela "hereditariedade" é possível entrar na "gênese" ou seja, na "causa" e no "curso" da doença fazendo a história da cidade e mostrando os seus momentos de crise; segundo, estudando-se os "vícios" e, por eles, identificando os "sintomas" é possível ver a deformidade dos órgãos afetados; terceiro, estudando-se o "temperamento" estabelece-se as proporções e as modificações entre os "elementos" que constituem a cidade, fornecendo-se assim o seu "caráter" próprio; quarto, pela "maneira de viver" tem-se o "regime" do organismo desequilibrado. Por último, de posse da "índole" do processo mórbido, o estudo das "necessidades" e do "desenvolvimento futuro" é o que revela $\circ$ próprio estado de carência e debilidade do organismo urbano, os desdobramentos possíveis da doença, e, portanto, os medicamentos preventivos e paliativos, as formas de intervenção e controle, o modo da convalescência. Ora, a analogia orgânica, a mesma que se aplica às partes de uma máquina, será duradoura. O próprio Alfred Agache vem ao Rio de Janeiro em 1927 reiterá-la: a cidade tem uma anatomia específica, é feita por terrenos, quarteirões, espaços livres, rios e mares; possui células, que são, obviamente, as casas, e, também, um sistema nervoso central, tipicamente urbano, representado pelos sistemas de correios, telégrafos e telefonia, a controlar e coordenar os movimentos. Mas a cidade ainda tem uma patologia específica: estes órgāos possuem funçōes que operam no sentido do desenvolvimento equilibrado do todo vital da cidade; tem uma função-circulação que precisa funcionar contra o problema da congestão; tem uma função-digestão, dada pelas canalizações e aparelhagem higiotécnica, que precisa ser desempenhada sob o risco da intoxicação; uma função-respiração, garantida pelos espaços livres que impedem a asfixia do organismo urbano, e por fim, uma musculatura entrevista não apenas pela saúde, mas pelos dados estéticos, pelas proporçōes harmoniosas, pelo equilíbrio do desenho ${ }^{27}$

O urbanismo desse modo é o produto de uma pesquisa que começa pela maneira de construir a cidade de nosso tempo para estabelecer a terapia adequada da cidade histórica. Saturnino de Brito, no entanto, faz uma leitura específica da obra de Camillo Sitte: não se trata apenas de criticar as plantas modernas, expor as suas chagas e marcar a distância face as antigas, mas de "interpretar" ou distinguir a maneira como o acaso e as tradiçōes artísticas operaram em algumas cidades do passado para produzir composições arquitetônicas de notável valor estético, por mais irregulares que sejam. Ao intérprete, munido de uma teoria da formação natural das cidades, cabe discernir o lado pitoresco dos parcelamentos produzidos pelo acaso para que eles não recaiam na fase prejudicial da construção meramente especulativa da cidade, mas que, ao contrário, objeto de um plano
(26) BONNIER, Louis. De L'Urbanisme. In: GAULTIEA, Op. cit. p. 224.

(27) AGACHE, A. O que é o urbanismo. In: Prefeitura do Distrito Federal. Cidade do Rio de Janeiro. Extensão, remodelaçāo e embelezamento. 19261930. Paris: Foyer Brésilien, 1930. 
(28) BRITO F. S. de. Le tracé sanitaire des villes: Technique sanitaire urbaine. 1916. In: Obras Completas, v. XX. Rio de Janeiro: Imprensa Nacional, 1944, p. 42-3.

(29) Idem, p. 61-2.

(30) OLIVEIRA, J. C. Saneamento das cidades. In: Boletim de Engenharia, n.6, v. IV. Recife, ago. 1930, anno VIII, p.132.

(31) Idem, p. 130.

(32) Idem, p. 137.

(33) GUEDES, P. Op. cit. 1928, p. 62. de conjunto, extensão mais saneamento, sejam previamente organizadas de modo a garantir as condições hodiernas, topográficas, locais, mas também sociais ${ }^{28}$ "Quand le terrain est plat, le tracé rectiligne, mais non rigide, avec avenues diagonals ou rayonnantes, doit être adopté de préférence parce qu'il facilite beaucoup le tracé des travaux sanitaires, la circulation, la police, l'orientation des passants,etc.; la collaboration de l'artiste Town Planner, au moment de l'organisation du plan ou plus tard, indiquera les modifications de détail qu'exige l'esthétique de la ville (...) Quand le terrain est accidenté on doit préférer naturellement les tracés irréguliers et mixtilignes, pour le mettre d'accord avec la topographie et les besoins à satisfaire, quant à l'écoulement des eaux et à la circulation des véhicules par des pentes convenables, on doit aussi considérer le bel effet du pittoresque naturel et prévoir l'embellissement ultérieur de la ville"29 A passagem fala por ela mesma, mas se ficarmos apenas com suas observaçōes sobre o relevo, que fornecem o substrato do partido urbanístico, tornam-se inteiramente compreensíveis as suas críticas ao Recife irregular, de um lado, e Belo Horizonte geométrica, de outro.

Essa idéia de reconciliação, no plano, entre o solo, o subsolo e a superfície, faria escola entre os engenheiros que escrevem no Boletim de Engenharia no Recife (Paulo Guedes Pereira, João Cleophas de Oliveira, José Estelita, Lauro Borba). É o próprio Guedes, o eugenista, quem cita este capítulo I do livro de Brito para insistir no aproveitamento artístico dos acidentes do terreno pelo "planejador de cidades" e condenar o rigorismo dos traçados, referindo-se inclusive a Exposition. O enxaguamento dos mangues e a drenagem superficial que ele propōe seguem a mesma regra: no sanear e aformosear, o respeito pelas linhas naturais de escoamento segundo os diversos tipos de baixios. Depressões, alagadas ou não, depressões influenciadas por marés, chuvas ou inundações, ou as de águas estagnadas, bacias pantanosas, lençóis subterrâneos - a relação entre o terreno e as águas é o indicador privilegiado no traçado higiênico da cidade.

Em Saneamento das cidades ${ }^{30}$ o engenheiro João Cleophas de Oliveira reafirma estas mesmas propostas de drenagem da cidade enquanto seguimento ao plano de Saturnino de Brito. Na verdade, temos aqui uma definição de urbanismo, ramo da engenharia sanitária, muito próxima da que se depreende dos artigos de Guedes. As funções do engenheiro certamente terão precedência em relação as do médico no equacionamento dos problemas urbanos, mas o combate às moléstias e transmisões e as obras de assistência social terão seu lugar ${ }^{31}$ "todo projeto de embelezamento está condicionado pelas exigências de hygiene e todas as matérias da vida da cidade (água e esgotos, escoamento, es paços livres, arborização, ajardinamento, tráfego, localização industrial, iluminação, etc.) subordinam-se ao ideal de saúde dos habitantes" ${ }^{32}$. Desse modo, ainda que o urbanismo seja aí definido como uma ciência e como uma arte, a função social do urbanismo impõe-se como fim e não resta dúvida que este é também uma questão de eugenia: "saúde da população" "progresso da raça" são os seus termos.

"A hygiene das cidades, o urbanismo fundindo n'uma só alma, a arte, a manifestação elevada do bello, pela visão sonhadora do architecto, á sciencia positiva do engenheiro, reclama o traçado geral da cidade para a confecção dos seus planos de embellezamento" ${ }^{33}$. Com Oliveira seria preciso reunir a arte dos arquitetos, a ciência do saneamento dos engenheiros e a eugenia dos higienistas. João Cleophas e Paulo Guedes dão a mostra da permeabilidade da engenharia sanitária a essa idéia de aperfeiçoamento do homem nacional. Não que o recurso ao saber médico conduzisse necessariamente à teoria eugênica, mas tal parece 
ter sido o argumento preferencial. Possivelmente o encurtamento crescente da "idéia higiênica" para o lado do controle sanitário das populações e das descendências, abriu cada vez mais espaço para uma intervenção autorizada dos engenheiros em um "urbanismo higiotécnico" abrangente e politicamente influente. Se os médicos higienistas nesse momento não se voltaram para matérias específicas como a mortalidade infantil, a tuberculose, a nosologia e campanhas sanitárias, a higiene escolar ou dos espaços de trabalho, eles assumiriam diretamente o problema da reprodução, da raça e da eugenia como naturalmente seu. Isso é evidente em artigos como o de Lins e Silva, "Eugenia e crime" (Revista Médica de Pernambuco, n.12, dez. 1931) ou o de Jorge Lobo, "Eugênica" (Jornal de Medicina de Pernambuco, n.10, out. 1932) Se, de um modo ou de outro, a "eugênica" fornecesse ainda nessa época, tanto mais no Recife de teorias raciais tão arraigadas, os parâmetros eminentes do argumento científico e perpassava como um espectro o pensamento da maior parte dos homens de ciência, os médicos constituiriam o seu maior porta-voz. Opção teórica e estratégia profissional malfadada: a medicina perderia em competência na escala dos saberes administrativos e no trato da "questão urbana"

\section{O Plano como Síntese de Saberes}

Em 1916, o arquiteto-urbanista francês Alfred Agache, autor do plano de Canberra, referia-se ao urbanismo como arte e ciência: enquanto arte, o urbanismo comportava uma parte de invenção pois era uma transposição e adapatação de todos os conselhos que os economistas, higienistas, engenheiros e arquitetos forneciam; enquanto ciência, o urbanismo comportava também o conhecimento da vida social e econômica das cidades pois era uma "recherce et organisation de tous les éléments qui entrent dans la composition d'une agglomération urbaine" ${ }^{34}$ Essa junção de formas de conhecimento distintas apareceria, porém, melhor estabelecida em sua primeira conferência no Rio de Janeiro, em junho de $1927^{35}$. O urbanismo é aí definido como uma espécie de polidez entre os regulamentos, planos e disciplinas; ele é uma ciência porque é um estudo metódico dos fatos e de suas causas; porque se funda na observação e decomposição dos fenômenos, do mais complexo ao mais simples; é uma arte por outro lado porque o produto dessas operações científicas precisa ser interpretado em uma síntese harmoniosa e bela, e apresentada à visão, exteriorizada, como se fosse uma pintura; mas o urbanismo é, agora, acima de tudo uma "filosofia social" não porque vise o aperfeiçoamento da espécie, mas porque trata da vida em comum, da coletividade, traduzindo para o francês, dos códigos de vizinhança, da polidez, tolerância, em uma palavra, da "urbanidade"

Agache começa a ser citado no Recife por outros dois artigos:" Comment reconstruire nos cités" e "Como se organiza o plano de uma cidade" Em carta aberta ao engenheiro Domingos Ferreira seu colega José Estelita, assíduo leitor do urbanista francês, escreve no Club de Engenharia, em agosto de 1927. o seguinte conselho: "Orientemos a evolução racional dos nossos núcleos urbanos"; evolução racional quer dizer: "o plano de uma cidade é uma obra de conjunto com o fim principal de estabelecer as directrizes que se impõem, permittindo modelar a cidade á medida de seu desenvolvimento e devendo essa obra de conjuncto ser estudada em função mathematica dos dados antropogeographicos, economicos e sociais bem definidos" 36 Dotado de competência, independência e autoridade suficiente, o autor do projeto da cidade é um "cientista" um raciocinador, e não menos um "artista", de experiência visual e prática acumulada,
(34) AGACHE, A. Les grandes villes et leur avenir. In: GAULTIER, L. Op. cit. p.239-40.

(35) Idem. O que é o urbanismo. Op. Cit.

(36) ESTELITA, J. In: Boletim de Engenharia, n. 10, v. II, Recife, ago. 1927, anno V, p. 251. 
(37) ESTELITA, J. Bairro de Santo Antonio, carta aberta ao distincto collega Domingos Ferreira. In: Boletim de Engenharia, n. 9, v. II, Recife, jun. 1927, anno V.

(38) Idem. Orientemos a evolução racional dos nossos núcleos urbanos. Op. cit., p. 262.

(39) AGACHE,A. Op. cit. 1917, p. 239.

(40) ESTELITA, J. Op. cit. ago. 1927, p. 262.

(41) Idem, Op. cit. jun. 1927, p. 240.

(42) Idem, Op. cit, ago. 1927, p. 250-1.

(43) AGACHE, A. Op. cit. 1917, p. 242. seja pelo exercício no canteiro seja pela atenção, pelo apuro do gosto e pela comparação desenvolvida nas viagens ao exterior. Mas, segundo Estelita, o urbanista deverá ter ainda grande propensão para os estudos econômicos, pois a reserva de recursos é indispensável à concepção e implementação de um plano. Nesse ponto, vale salientar, a finalidade social do urbanismo não coincide totalmente com o de Agache: aliás, uma das grandes objeções à sua contratação em outubro de 1927 para a elaboração do projeto de remodelação e desenvolvimento do Recife, quando de sua visita à cidade, teria sido o orçamento elevado dos custos aventados. É preciso propagandear o que significa essa "sciencia das cidades" no Recife, pois "o grande público não suspeita que seja possível nos dias correntes conciliar a sciencia, a arte e igualmente os interesses das finanças" 37

Já que o urbanismo é coordenação de todos os fatos de um agregado urbano, o novo regime edilício deverá ser informado então pelo conhecimento das rendas públicas: "é por isto mesmo um problema eminentemente de engenharia cuja solução exige de nós, engenheiros civis, um estudo de analyse e um estudo de synthese: a escolha ou classificação de elementos ou grupos de elementos formadores de uma cidade e em seguida o estabelecimento inductivo de leis que a nossa observação cuidadosa e experiência diária precisam descobrir para os seus melhoramentos attenderemas necessidades mais modernas e anteciparem sobre o seu futuro proximo" "38. Estelita aqui parafraseia Agache em sua conferência da Exposition de la Cité Reconstituée ${ }^{39}$. Dotados de olhar clarividente, os engenheiros serão vistos como os "evangelizadores" da nova ciência, "estimulando o progresso material das localidades brasileiras sob os effluvios bemfazejos do nosso sentimento patrio e com a positividade, 0 alcance, a clareza, o equilibrio dos conhecimentos scientificos emanados da nossa razão esclarecida" ${ }^{40}$.

\section{A Urbanística Moderna, Visões do Acaso e da Política}

A crítica da improvisação e do improviso, portanto, a pedra de toque do discurso planejador. "Resolver em assumptos technicos improvisadamente, isto é, sem o estudo amadurecido das questões, sem a discussão prévia dos seus pontos capitaes, é um grande erro, maxime em se cogitando de technica urbana que, por sua natureza, do mesmo modo que um tratamento de um caso no organismo animal, exige o concurso inseparável e a cada momento, da consciência e da sciencia" 41 Donde o plano ser a grande arma dos engenheiros modificados em urbanistas. Nem a consciência nem a ciência podem ser postos à prova de "esforços de flexão, cisalhamento ou escorregamento" sob o risco de recaírem na "sofística" e arruinarem os propósitos do plano. A comparação com a oratória redobra o discurso competente sobre si mesmo: Estelita compara o acaso com os riscos de toda obra civil mal estabelecida, é um retórico, por excelência; em seguida, compara o discurso imprevidente dos liberais com o sofisma. Frêmitos de entusiasmo e surtos de eloqüência podem emprestar a uma peça improvisada um efeito encantador; " na engenharia porém, a coisa muda muito de figura e não haverá rasgos de dialectica ou devaneios de rethorica capazes de resolver improvisadamente um caso que pela sua gravidade mereça investigação acurada, alguma sobriedade e muita reflexão" 42 . O risco da sedição é tanto maior quanto mais impregnado em nossa cultura é o recurso ao improviso. É interessante que - improviso seja também qualidade francesa: "L ímprovisation - cette qualité éminemment française - n'est pas de mise en matière urbaine; il faut prévoir, et prevoir à longue échéance" 43 
Mas a técnica urbana tem um outro adversário, melhor estabelecido e visível: a política, o partidarismo político, as oscilações dos governos. Tal como o improviso, a política é vista como espaço de elasticidade - a metáfora das extensões, torsões e flexões também é aqui recorrente-inadmissívelà ciência das cidades. O sopro mágico do acaso é religado aos caprichos da política e as facilidades do tempo contrapostas ao rigor técnico.

A queixa quanto ao urbanismo francês, procede também certamente do fato de ser este ainda retardatário. O próprio Agache difunde a hipótese do atraso francês e reivindica para si a autoria do neologismo. De fato, "urbanisme" só apareceria durante a guerra e sob a suspeita dos especialistas. A pergunta De Bonnier em 1916 demonstra inquietação: Vocês, meus colegas, sem dúvida conhecem o livro Capital de Camillo Sitte, o de Souza sobre Nice, os trabalhos de Abbercrombie, de P. Geddes, de Raymond Unwin, dos americanos, também de alguns alemães, como o nosso precursor Stubben? Daí nasceram os grandes concursos internacionais e o triunfo de alguns de nossos camaradas, Jaussely, Prost, Bérard, Tony-Garnier, Auburtin, Agache ${ }^{44}$

Ora, a definição do plano deverá então retornar eventualmente aos mestres. José Estelita nos oferece um leitura lateral aos escritos franceses. Retoma, via Saturnino de Brito, a obra de Nelson Lewis, e através deste, a crítica de Abbercrombie à orientação francesa em matéria de organização urbanística e tráfego. Lewis é, aqui, indubitavelmente, a fonte mais autorizada por Estelita.

Por sua vez, senão teorica ou juridicamente, ao menos administrativamente, o urbanismo alemão fornece o exemplo a ser seguido. Estelita retoma o artigo de Descroix, na Revista L'Eau, sobre a relação entre política e urbanismo: na Alemanha, os prefeitos são indicados pelo governo central; prefeito eleito, aliás, é mero objeto de eleitores, adversário de seus contrários, prisioneiro de um partido, beneficiário dele e adversário de muitos ${ }^{45}$. Motivos iguais, portanto, na França e no Brasil: a) incompetência dos chefes comunais; b) arbitrariedade dos líderes de facção; c) instabilidade de opiniões, mandatos e do próprio regime de oposições. É evidente que se faz, em um caso como no outro, uma apologia ao sistema de nomeação dos prefeitos, o que se coaduna, lembra Estelita, com o sistema vigente em algumas capitais estaduais brasileiras. Assim, em nome da técnica urbanística, pode-se fazer discurso político: "Fazemos nossas e dirigidas aos legisladores pernambucanos as solicitaçōes feitas na mencionada revista technica aos poderes legislativos da França por aquelle scientista no sentido de uma reforma radical no regimen a exemplo do que se executa ha muitos annos na Allemanha" 46 Nos tempos de Vauthier, seu discurso soaria no mínimo como imperdoável insolência, senão como crime de lesa-pátria. Se o radicalismo dos urbanistas prima pela gestão eminentemente técnica do espaço público; a associação recorrente entre democracia e demagogia é compreensível: sob a aparência da liberdade, a política esconde o império de uma das partes; sob o processo eleitoral, esconde a inconstância e ineficiência das administrações; sob a face representativa, esconde a ausência de critérios científicos, o improviso e o desperdício de recursos públicos. Donde, curiosamente, a necessidade da inserção institucional dos engenheiros enquanto "os mais competentes" dentre todos.

Só assim, a planta da cidade aparece como um limite entre a imprevisibilidade e a engenharia urbana, como instância a partir da qual a cidade não será mais o espaço do acaso. A planta é requisito do plano. Parece que também este, requisito do governo conveniente do espaço, tornar-se-á, gradualmente, condição daquela. Sem o plano não se pode presidir a vida, modificação e expansão da
(44) BONNIER, L. op. cit. p. 228.

(45) ESTELITA, J. Orientemos a evolução racional dos nossos núcleos urbanos. In: Boletim de Engenharia, ก.10, v. II, Recife, ago. 1927. p. 259.

(46) Idem, p. 260. 
cidade; sem a planta não se pode conhecer esse processo. Materialização do estado geográfico e sanitário do assentamento, ela pretende subsidiar o plano urbanístico, ou seja, é feita para ser por ele negada. E ela também o nega nas múltiplas folhas e nos múltiplos marcos que estabelecem os limites gráficos e geodésicos de intervençāo segura na cidade, sem contar que, sempre inacabada, - elemento imprevisível ameaçador do espaço público nem sempre vêm às luzes do traçado. Ao fim e ao cabo, talvez a planta e o plano também sejam operaçōes que de um modo secreto se anulam, embebidas do sonho contumaz de uma cidade inteira e perfeitamente governada.

* Subsídios à tese em elaboração sobre "mocambos" e "habitação higiênica" no Recife, entre 1909 e 1939, orientada pela Profa Dra Maria Ruth Amaral de Sampaio. 